Vol. 11, No. 38, January, 2016, 33-43

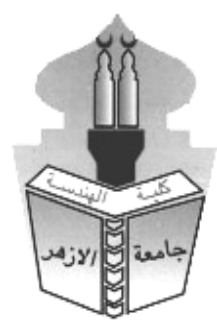

\title{
TOWARDS CONSTRUCTION OF SPECTRAL LIBRARY OF URBAN SURFACE MATERIALS BASED ON SPECTROSCOPY
}

\author{
Ahmed Ibrahim Ramzi \\ National Authority of Remote Sensing and Space Science (NARSS)
}

\begin{abstract}
Urban areas contains complex and high diversity of built-up and non built-up materials, involves horizontal and inclined surfaces like roads and roofs. For this purpose, spectra of the main urban surfaces (i.e. roofs and pavement materials) should be measured. Spectra acquired from an imaging platform, field and laboratory. In this study field spectra have been acquired directly using an ASD field 3 spectrometer instrument. Also, Spectra measurements of urban surface materials have been measured in the laboratory for small samples brought from field represented urban surface using two spectral comers VINIR Visible Near Infrared and Short Wave Infrared SWIR. Also, spectra have been acquired from satellite and airborne sensors; Landsat Enhanced Thematic Mapper ETM+, Hyperion Earth Observing EO-1 and Hyspex camera. The selected study area located in Cairo, Egypt has a complex urban land use / Land cover LU / LC. The main objective is to develop, spectral library from imaging system, field and laboratory measurements. Spectral library proposed to be used for calibrating and validating hyperspectral data and for the purpose of accurate detection surface materials and improve results of classification of urban surfaces. The methodology involves divided urban surfaces into two main classes built up and un-built up areas. Each main class has been divided into sub classes according to materials, taken into consideration cowmen materials. After that develop sample strategies, measurements in situ, processing and construct a spectral library. The results show that there was considerable spectral confusion between urban land cover types (i.e. specific roof and road types). Construction complete spectral libarary for any country is very essential for many remote sensing applications but it is hard task and very expensive and timely.
\end{abstract}

\section{Keywords : Multispectral - Hyperspectral - Remote sensing, - Urban feature materials - Spectral library}

\section{INTRODUCTION}

One of the most critical steps in most imaging spectrometer data analysis strategies is to convert the data to reflectance, principally so that individual image spectra can be compared directly with laboratory or field data for identification and verification. Analysis of spectroscopic data from field, laboratory, aircraft, and spacecraft instrumentation requires a knowledge base. The spectral library forms a knowledge base for the spectroscopy of minerals and related materials. Field spectroscopy has a role to play remote sensing and useful in: librating airborne and satellite sensors, predicting the optimum spectral bands and refinement and testing of models. A number of high quality field instruments are available such as Spectron-SE590, ASD Personal Spectrometer II, GER Field Spectrometer Mark IV and ASD full range instrument. Spectra measured on the ASD spectrometer used a directional light source and fiber-optic probe to collect light. The incidence angle was variable but typically ranged from 20 to 40 degrees, as did the emission angle. Spectra are corrected to absolute reflectance by using a Spectralon standard with correction methods. Field spectra measured using the ASD spectrometer has been collected under various sky conditions. Most are collected under optimum conditions of clear skies and within an hour of noon. Because of limited time for field work, some spectra have been 
collected under partly cloudy skies and up to 3 hours before or after solar noon (USGS 2013). Spectra are acquired at three scales, in-situ, laboratory and Imaging platform (Roberts, D.A., and Herold M., 2004). Multispectral data has a limited number of spectral bands not more than 20 bands. Hyperspectral data has a high spectral resolution, It deals with imaging at narrow and large number of spectral bands more than 100 bands. Airborne hyperspectral imaging systems are widely used for environment research applications since the development of imaging spectrometers such as AVIRI and HyMap Hyperspectral (Cocks, T., et al., 1998). The Spectral characteristics of urban surfaces are known to be complex. Hyperspectral data offer capabilities of improved spectral and spatial urban mapping capabilities (Herold M ., et al., 2004). Surface materials can be detected on a very detailed level from the hyperspectral imagery (Chisense C., 2012, Buckingham et al., 2002). In urban environments sampling strategies was complicated. The simplest sampling problem involves horizontal surfaces, such as roads, parking lots, sidewalks or lawns. In this instance, the height of the instrument and number of measurements required will depend on the variability of the surface and the objectives of the measurements. For example, a relatively uniform, newly surfaced parking lot may require very few measurements to capture its spectrum. In contrast, if the objective is to quantify very fine scale variability, such as the impact of cracks on a road surface, many measurements may be required with the instrument positioned close to the surface (a few tens of $\mathrm{cm}$ ). For example, to sample roof spectra the instrument may have to be transported to the roof. Instrument height will vary depending upon the degree of purity desired. If the objective is to sample one shingle, the height and foreoptic must be selected to restrict the field of view to the small illuminated portion of the shingle. If the objective is to capture multiple shingles, or shadows cast, by a shingle, a larger fore-optic or higher sensor height must be selected. Vertical structures and non-horizontal surfaces, which are common in urban environments, provide considerably greater challenges. Vertical surfaces, such as plants add additional complications, such as variable heights of surfaces and considerable variation in shadowing, leaf orientations, branches etc. In order to characterize this variability, we typically sample multiple spectra, within a single plant, and multiple plants within a species (Roberts et al. 1985, 1993, 1998 and 2004). To capture variability within a single roof, multiple spectra may be required on the same roof aspect, or spectra may be required on different aspects on the same roof. Imaging spectrometry is a rapidly evolving field in which new sensors and new analysis methods are continually being developed (Roberts, D.A., and Herold M., 2004). In this study field based spectra were acquired directly using an ASD field 3 spectrometer instrument. Also, Spectral measurements of urban surface materials have been measured directly from field using ASD field 3 spectrometer. Supervised classification has many techniques to classify remote sensing data. Spectra Signature of Urban feature materials can be obtained from USGS library or from own library. Verifying and evaluating the added value of of the high spatial resolution and multi/hyperspectral sensors in mapping and distinguishing different surfacing materials in a complex urban context by constructing a spectral library of urban materials (Rosa M. C. et al. 2008). Atmospheric correction of hyperspectral data is mandatory for conversion of radiance to reflectance Therefore, in this study, atmospheric correction was first conducted to retrieve surface reflectance from data of hyperspectral sensor Hyperion (Gerylo, G.R., et al., 2002).

\section{1- In-situ Spectra}

Spectra acquired from Field (termed in-situ Ben-Dor, E.,, 2001) using Field Spec 3 Portable Spectroradiometer

The FieldSpec ${ }^{\circledR} 3$ offers the modular Goetz spectrometer with a spectral range from $350 \mathrm{~nm}$ to $2500 \mathrm{~nm}$ and is ideally for numerous remote sensing and research applications. Figure (1) shows ASD portable spectroradiometer field Spec 3 model HR (High Resolution)._Table (1) shows specifications of ASD portable spectroradiometer FieldSpec 3. 


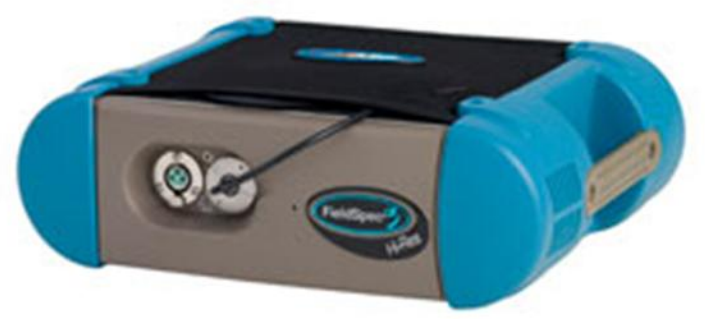

Fig. (1) ASD portable spectroradiometer field Spec 3 model HR

Table (1) Specifications of ASD spectroradiometer Field Spec 3, model HR Portable

\begin{tabular}{|c|c|}
\hline Spectral Range & $350-2500 \mathrm{~nm}$ \\
\hline $\begin{array}{l}\text { Spectral } \\
\text { Resolution }\end{array}$ & 3 nm @ 700 nm; 8.5 nm @ 1400 nm ; 6.5 nm @ 2100 nm \\
\hline Sampling Interval & 1.4 nm @ 350-1050 nm; 2 nm @ 1000-2500 nm \\
\hline Scanning Time & 100 milliseconds \\
\hline Detectors & 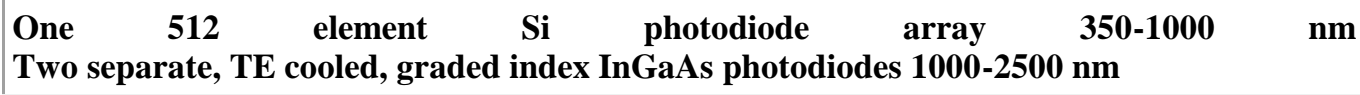 \\
\hline Input & $\begin{array}{l}1.5 \mathrm{~m} \text { fiber optic }\left(25^{\circ} \neg \text { field of view) }\right. \\
\text { Optional foreoptics available }\end{array}$ \\
\hline $\begin{array}{l}\text { Noise Equivalent } \\
\text { Radiance (NEdL) }\end{array}$ & $\begin{array}{l}\text { UV/VNIR } 1.1 \times 10-9 \mathrm{~W} / \mathrm{cm} 2 / \mathrm{nm} / \mathrm{sr} @ 700 \mathrm{~nm} ; \text { NIR } 2.2 \times 10-9 \mathrm{~W} / \mathrm{cm} 2 / \mathrm{nm} / \mathrm{sr} @ 1400 \mathrm{~nm} \text {; } \\
\text { NIR 4.0 } 10-9 \mathrm{~W} / \mathrm{cm} 2 / \mathrm{nm} / \mathrm{sr} @ 2100 \mathrm{~nm}\end{array}$ \\
\hline Weight & $12 \mathrm{lbs}(5.2 \mathrm{~kg})$ \\
\hline Calibrations & $\begin{array}{l}\text { Wavelength, reflectance, radiance*, irradiance; All calibrations are NIST traceable } \\
\text { (*radiometric calibrations are optional) }\end{array}$ \\
\hline
\end{tabular}

\section{2- SPECTRA ACQUIRED FROM LABORATORY MEASURMENTS}

Laboratory based measurements are made over a fairly small sample. Samples collected from field and brought into the laboratory. The advantage of using samples collected from field and brought into the laboratory. It is providing controlled conditions and the highest quality reflectance, but also require the transport of surfaces into the laboratory environment.

Hyperspectral VINIR and SWIR Laboratory Camera

One should mention her that this is the first time using Lab Camera VNIR and SWIR for built spectral library.

1- Spectral Camer VINIR. Model: Digital CCD Camera ORCA- 05G

The Camera ORCA- 05G is a high resolution digital camera using a progressive scan interline CCD with no mechanical shutter. Lab VNIR camera offering an extended wavelength range from $400-1000 \mathrm{~nm}$.

Lab Camera VNIR has the following spec:

Total no. of bands $=476$ from $400-1000 \mathrm{~nm}$

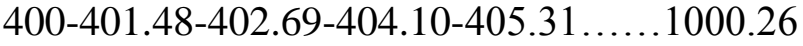

B1 400.4800

B2 401.6900

B3 402.9000

B474 997.6300

B475 998.9500

B476 1000.2600

\section{2- Spectral Camera SWIR Model SPECIM}

The SPECIM SWIR camera is one of the most versatile cameras offering an extended wavelength range. SWIR Short-wavelength infrared is from $900-2500 \mathrm{~nm}$, that provides the accuracy required in today's most challenging nearinfrared chemical imaging applications, from pharmaceutical quality assurance to food and agriculture analysis and Process. 
Lab Camera SWIR has the following spec:

Total no. of bands $=256$ from $900-2500 \mathrm{~nm}$

913.78-920.10-926.42-932.74_.....2514.34

B1 913.7800

B2 920.1000

B3 9264200

B254 2501.8701

B255 2058.1001

B256 2514.3401

3- Spectra Acquired from Imaging Platform

Imaging platform (Satellite or airborne sensors)

Imaging platform (Satellite or airborne sensors)

In contrast to traditional multispectral sensors such as Landsat-TM, Spot-MX or IRS-LISS that collect spectral data in a few spectral bands (less than 20 spectrally discontinuous channels). Airborne HySpex cameras based on know-how acquired by NEO has been used in a wide range of applications such as geology, vegetation, glaciology, oil spills, environmental, urban planning, governmental, forestry, search and rescue and military (Hyspex, 2010).

\section{a-ETM+ (Enhanced Thematic Mapper)}

Landsat 7 (ETM+), 7 multispectral bands and wavelength rang from 0.45 to2.35 micrometers and spaial resolution $30 \mathrm{~m}$.

\section{b- Hyperion Imaging Spectrometer EO-1 Hyperspectral Satellite-borne}

The EO-1 spacecraft is in sun-synchronous orbit at $705 \mathrm{~km}$ altitude flying 1 minute behind Landsat 7 passing over the equator in descending node at 10.01 AM.

The Earth Observing 1 (EO-1) satellite has three imaging sensors: the multispectral Advanced Land Imager (ALI), the hyperspectral Hyperion sensor, and the Atmospheric Corrector. Hyperion is a high-resolution hyperspectral imager capable of resolving 220 spectral bands (from 0.4 to 2.5 micron) with a $30 \mathrm{~m}$ resolution. The instrument images a $7.5 \mathrm{~km}$ by $100 \mathrm{~km}$ surface area. Hyperion is a pushbroom spectral radiometer with two spectrometers that share the same fore-optics. A VNIR CCD senses the first 70 bands (400-1000 nm) and an HgCdTe SWIR detector senses channels 71-242 (900-2500 nm). Table (2) shows sensors specifications of (EO-1) satellite.

Table (2) Sensors specifications of (EO-1) satellite

\begin{tabular}{|l|c|c|c|}
\hline \multirow{2}{*}{\multicolumn{1}{c|}{ Parameters }} & ALI & HYPERION & AC \\
\cline { 2 - 4 } Spectral Range & $0.4-2.4 \mu \mathrm{m}$ & $0.4-2.4 \mu \mathrm{m}$ & $0.9-1.6 \mu \mathrm{m}$ \\
\hline Spatial Resolution & $30 \mathrm{~m}$ & $30 \mathrm{~m}$ & $250 \mathrm{~m}$ \\
\hline Swath Width & $36 \mathrm{Km}$ & $7.6 \mathrm{Km}$ & $185 \mathrm{Km}$ \\
\hline Spectral Resolution & Variable & $10 \mathrm{~nm}$ & $6 \mathrm{~nm}$ \\
\hline $\begin{array}{l}\text { Spectral Coverage } \\
\text { Pan Band Resolution }\end{array}$ & Discrete & Continuous & Continuous \\
\hline $\begin{array}{l}\text { Total Number of } \\
\text { Bands }\end{array}$ & $10 \mathrm{~m}$ & N/A & N/A \\
\hline
\end{tabular}

\section{c- Airborne HySpex Cameras Hyperspectral Cameras}

HySpex, NEO's line of hyperspectral cameras, aims to offer compact, high performance and versatile instruments for a multitude of applications, including airborne, laboratory, field and industrial use of imaging spectroscopy.

Band (SWIR) 400- 1000nm

Spatial Resolution $=1.5 \mathrm{~m}$

Bands $=256$ band 
Band (VNIR)1000-2500 nm

Spatial Resolution $=0.38 \mathrm{~m}$

Bands $=160$ band

Table (3) shows characteristics of Hyspex Airborne camera

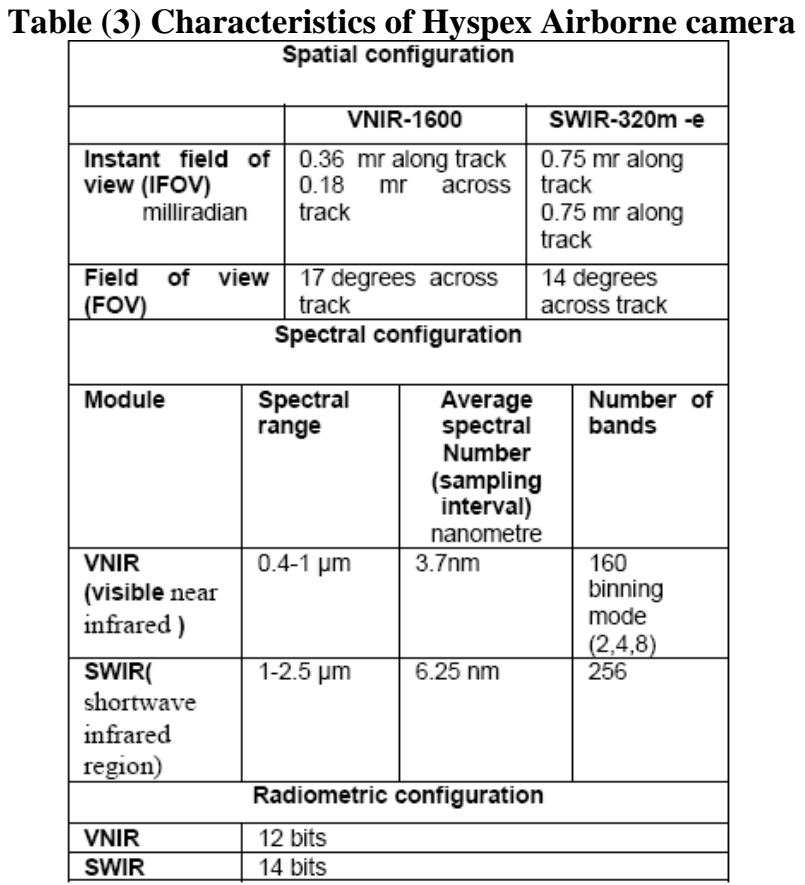

\section{STUDY AREA}

(Hyspex 2010, Lamyaa T. and Atti S., 2013)

In-situ spectra acquired from directly from field has been performed using ASD. The selected study area located in and around the main building of National Authority of Remote Sensing and Space Science (NARSS), Cairo, Egypt. Also, Laboratory based measurements have been carried out over samples collected from the same study area and brought into the laboratory. Spectra acquired from satellite imaging platform ETM+ and Hyperion EO-1 located in complex urban area in Cairo. Spectra acquired from airborne imaging platform Hysepx located in south east Aswan, Egypt

\section{Methodology}

In this part of research, one can propose development of a spectral library for urban area using imaging spectrometry to map the selected area, Putting sample strategies for urban areas will be taken into consideration. Urban areas complicated and involves horizontal surfaces like roads and roofs. First of all, the urban feature main materials were classified and identified. Main Classes: Built-up surfaces, Non built-up surfaces, Water body. Sub Classes of built-up surfaces: Roofs and roads. Roofs like: R.C. slab, concrete tiles, wood, steel sheets, plastic sheets and other tiles. Roads like: asphalt, P.C., cement tiles, red tile and cement bricks. Sub Classes of Non built-up surfaces: water, vegetation and top soil. Sub Classes of water body: salt water and fresh water. Top Soil like: clay, silt, sand, mixed soil, rocks and wet soil. Vegetation like: trees, crops, grass and dray vegetation.

In this research, four types of spectral radiometers have been used which are:

1. ASD spectroradiometer FieldSpec 3

2. Hyspec VNIR Camera Model: Digital CCD Camera ORCA- 05G

3. Hyspec SWIR Camera Specim

4. Imaging system

- Landsat ETM+ satellite imagery

- Earth observing satellite Hyperion EO1imagery 
- Airborne HySpex hyperspectral cameras

Processing of ASD Field Spectra

In order to prepare raw spectra measured with an ASD field spectrometer for further use. The following basic sequence of processing steps has to be performed:

$>$ Design sample strategy

$>$ Data collection from field

Detailed metadata recorded for our urban spectra included:

$>$ Photographs should be acquired

$>$ GPS location

$>$ Short description of the material

$>$ Time of day,

$>$ Raw ASD spectra

$>$ Create spectral library using ENVi software

$>$ Spectralon corrected library

A reflectance spectrum is measured as percentage of reflectance with respect to a white reference panel, usually made of spectralon. In reality, the white reference panel shows a reflectance slightly below $100 \%$ and its spectral properties vary over wavelength. Since the target reflectance is measured relative to the reflectance of the spectralon panel (white reference), it is slightly overestimated and has to be correct.

$>$ Library without erroneous spectra or Remove erroneous spectra

Some spectra contain measurement errors, for example caused by a Field spectrometer malfunction or cloud cover. These need to be removed, because they falsely influence the average of spectra of a target.

$>$ Processed spectral library

Design of sampling strategy

Sampling strategy is the key in the field the following criteria and consideration in collecting sample should be include:

$>$ Sample Naming

have tried to use only proper mineral names as given in (Fleischer 1980), (Fleischer and Mandarino 1995), and (Klein and Hurlbut 1999).

$>$ Sample Documentation

Each spectrum has a sample description page describing the origin and sample purity from available data.

$>$ Sites, classes of sample and number of samples

In urban environments sampling strategies can be complicated. The simplest sampling problem involves horizontal surfaces, such as roads, parking lots, sidewalks or lawns. In this instance, the height of the instrument and number of measurements required will depend on the variability of the surface and the objectives of the measurements. For example, a relatively uniform, newly surfaced parking lot may require

$>$ The choice of fore-optics, height above the target, frequency that spectra are standardized,

$>$ time of day,

$>$ acceptable atmospheric

$>$ Conditions and number of samples for each target.

$>$ Ideally spectra should be acquired when:

-Solar zenith is lowest within $+/-2$ hours of solar noon.

-Clear sky conditions,

$>$ Range of acceptable times will depend on latitude, time of year and the frequency at which standards are measured. At higher latitudes, the acceptable range will be far 
shorter during the winter, but may be greater during the summer. Assumes a 5\% change in radiance measured between standards is acceptable).

$>$ Reflectance standards should also be acquired under the same illumination conditions as the surface to avoid the impact of side scattered light.

$>$ For example, if a target is measured in close proximity to a tree, but the standard is measured away from the tree, the lighting environment of the target will include higher levels of NIR than the standard, thus producing an anomalous spectrum (side scattered radiation is also called the adjacency effect). Adjacency effects will be most significant in rough urban environments.

\section{Processing of Satellite Images}

Remove bad bands and layer stacking. After that, radiometric correction and atmospheric corrction using Flaash model. Extract spectra of different urban featuers. Built spectral library

\section{RESULTS}

The proposed methodology has been applied step by step and the obtained results will be presented down. The urban feature main materials were identified in table (4). Table (4) represents example for inventory of urban classes and materials for complex urban for the selected study area near NARSS buildind. As mentioned before, spectra can be acquired at three scales in-situ Spectra, laboratory measurements and imaging platform. Figure (2) shows spectral library using ASD spectro radiometer FieldSpec 3. Figure (3) shows spectral library extracted from laboratory measurements hyperspectral camera VNIR and SWIR. Figure (4) shows spectral library from satellite image ETM+. Figure (5) shows spectral library from Hyperion EO-1. Figure (6) shows spectral library for three different topsoil materials have been extracted from airborne Hyspex camera VNIR and SWIR.

Table (4) Urban classes and materials

\begin{tabular}{|c|c|c|c|}
\hline Main Class & Sub Class & S.N. & Material \\
\hline \multirow{14}{*}{ Built-up surfaces } & \multirow{7}{*}{ Roofing } & 1 & R.C. Slab \\
\hline & & 2 & Concrete Tiles \\
\hline & & 3 & Other Tiles \\
\hline & & 4 & Steel Sheets \\
\hline & & 5 & Plastic Sheets \\
\hline & & & Red Bricks \\
\hline & & 6 & Wood \\
\hline & \multirow{7}{*}{ Road } & 7 & Asphalt \\
\hline & & 8 & P.C. \\
\hline & & 9 & Cement Tiles \\
\hline & & & Red tile \\
\hline & & 10 & Other Tiles \\
\hline & & 11 & Asphalt + sand \\
\hline & & 12 & Cement Bricks \\
\hline \multirow{10}{*}{$\begin{array}{l}\text { Non built-up } \\
\text { surfaces }\end{array}$} & \multirow{4}{*}{ Vegetation } & 13 & Trees \\
\hline & & 14 & Crops \\
\hline & & 15 & Grass \\
\hline & & 16 & Dray Grass \\
\hline & \multirow{6}{*}{ Soil } & 17 & Clay \\
\hline & & 18 & Rocks \\
\hline & & 19 & Silt \\
\hline & & 20 & Mixed soil \\
\hline & & 21 & Wet land \\
\hline & & 22 & Sand \\
\hline \multirow[t]{2}{*}{ Water body } & \multirow{2}{*}{ Water } & 23 & Salt Water \\
\hline & & 24 & Fresh Water \\
\hline
\end{tabular}



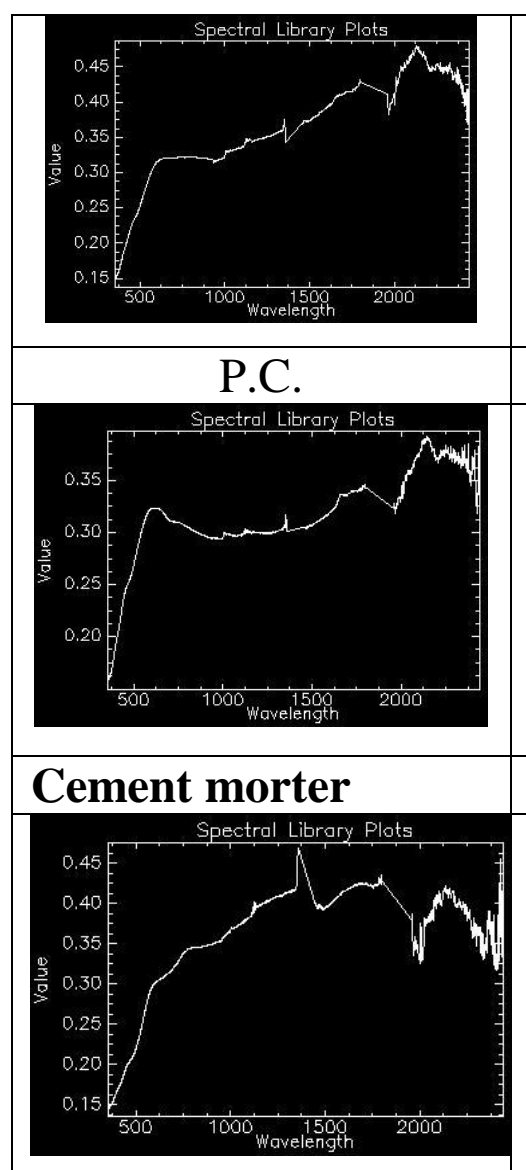

Platform tiles

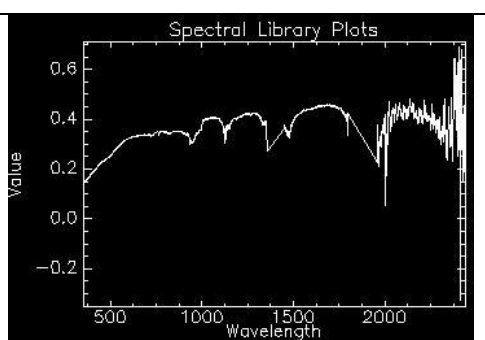

R.C.
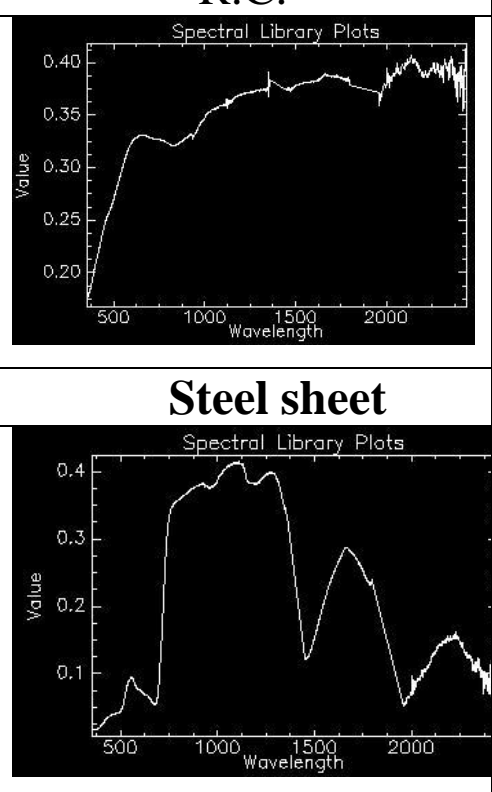

Vegetation

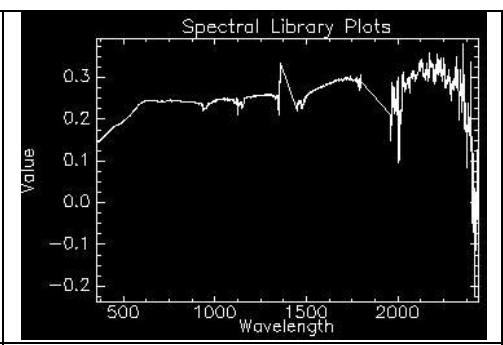

Cement tile

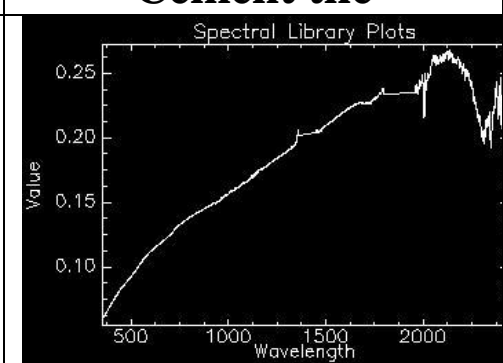

Asphalt

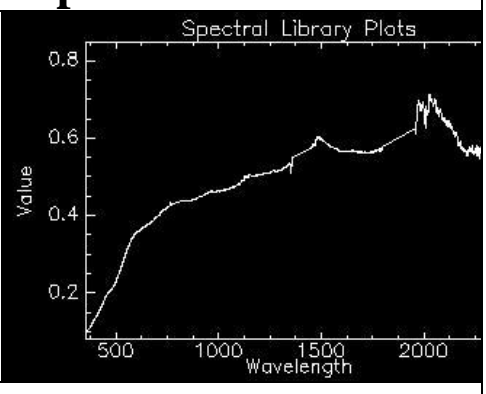

Sand

Fig. (2) Spectral library using ASD spectro radiometer FieldSpec 3

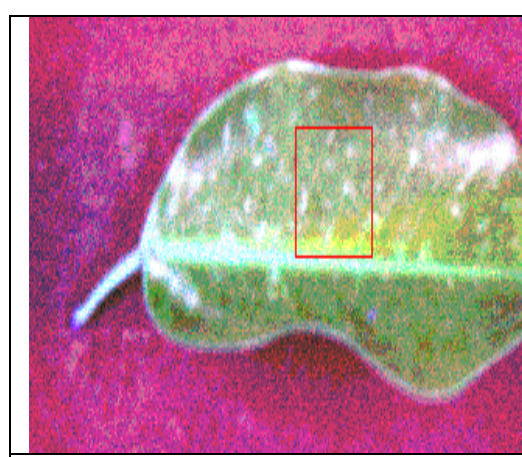

vegtation

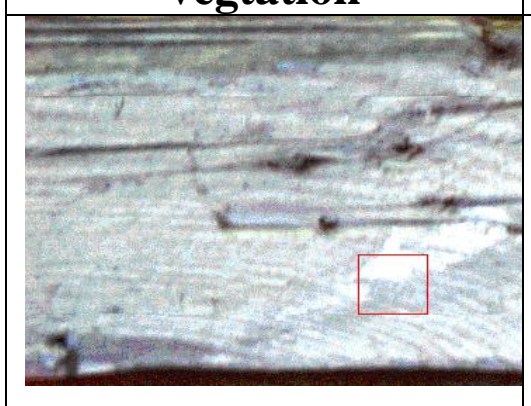

Dry wood
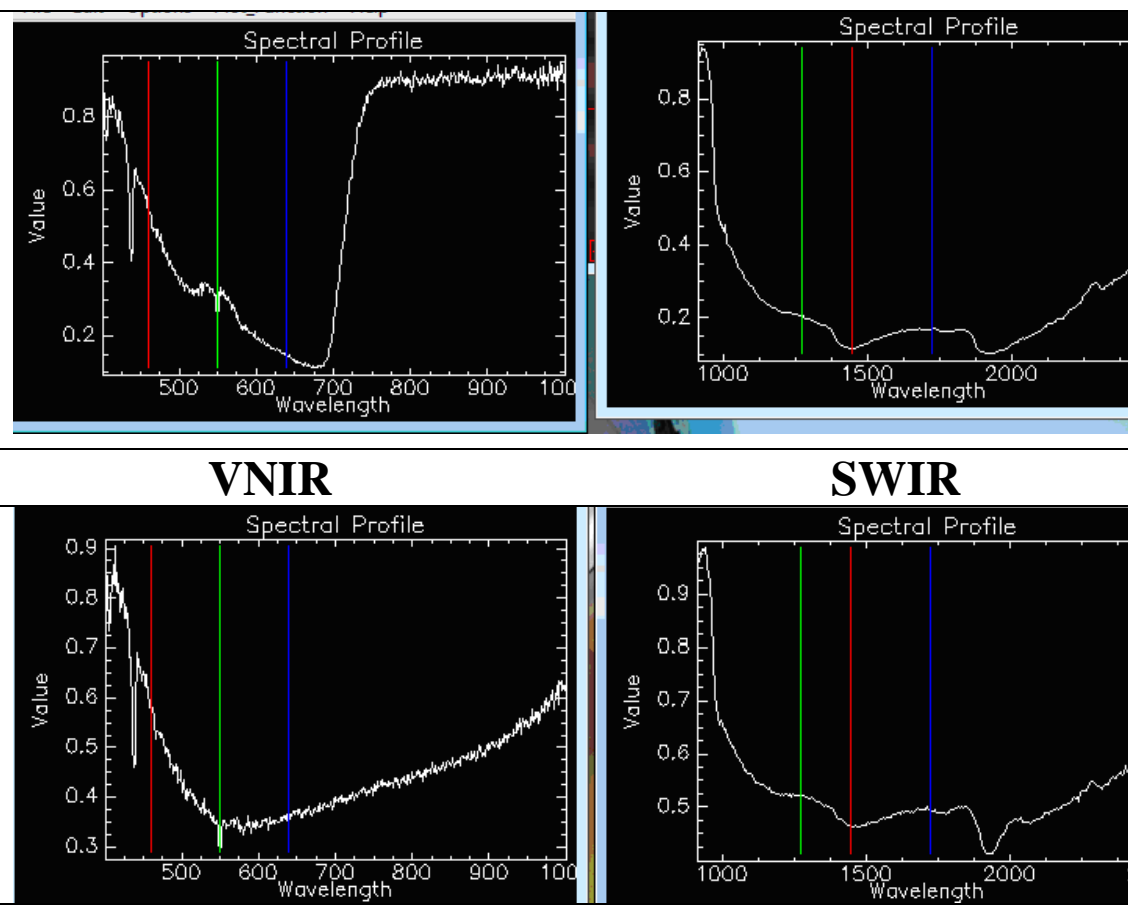

VNIR

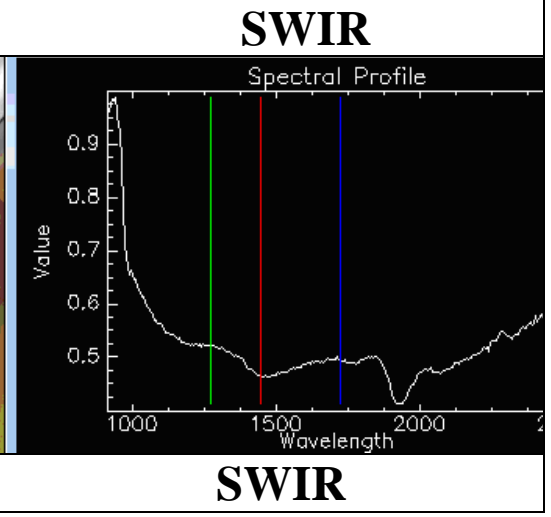


TOWARDS CONSTRUCTION OF SPECTRAL LIBRARY OF URBAN SURFACE MATERIALS BASED ON SPECTROSCOPY

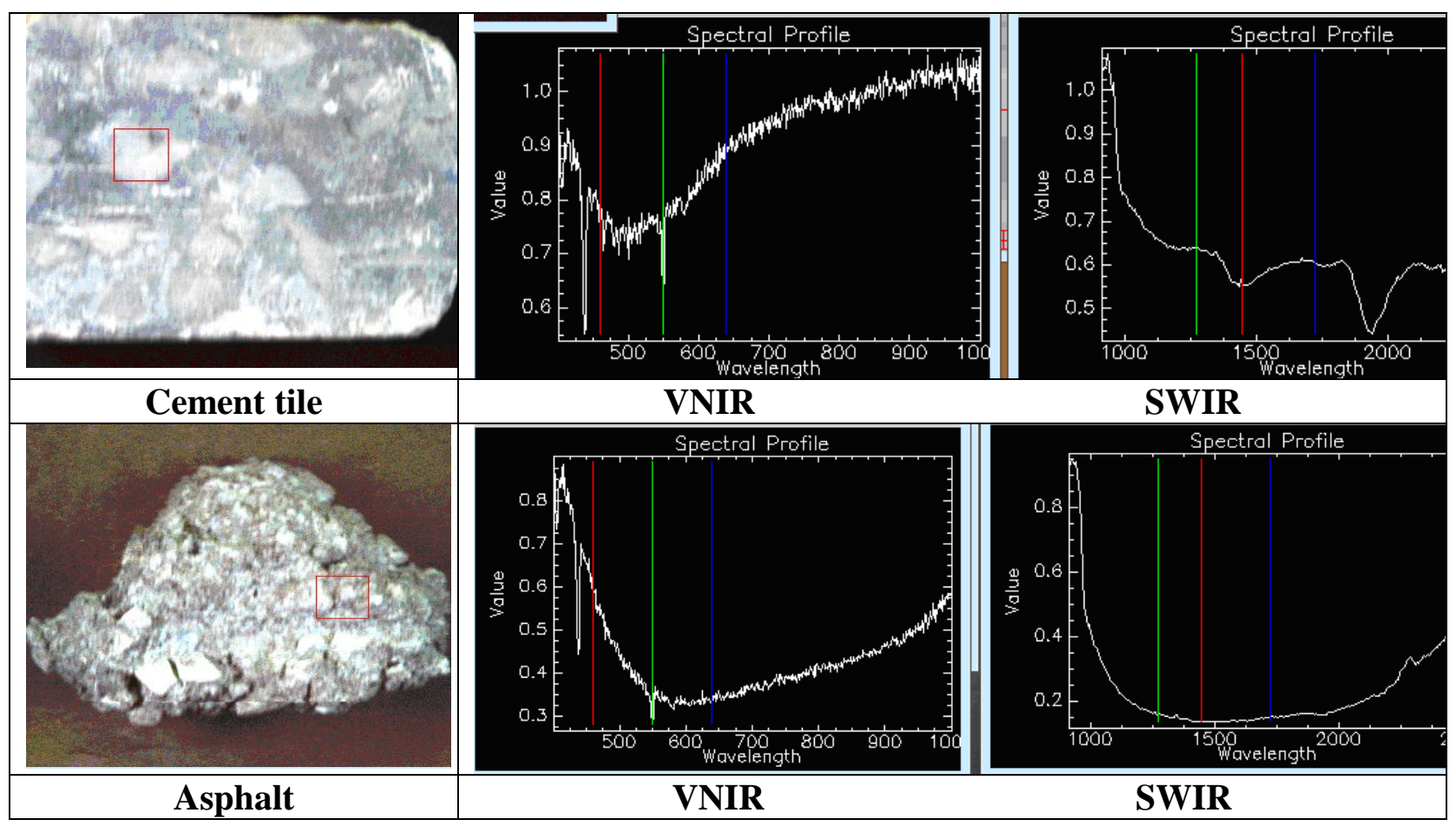

Fig. (3) Spectral library extracted from laboratory measurements hyperspectral camera VNIR and SWIR
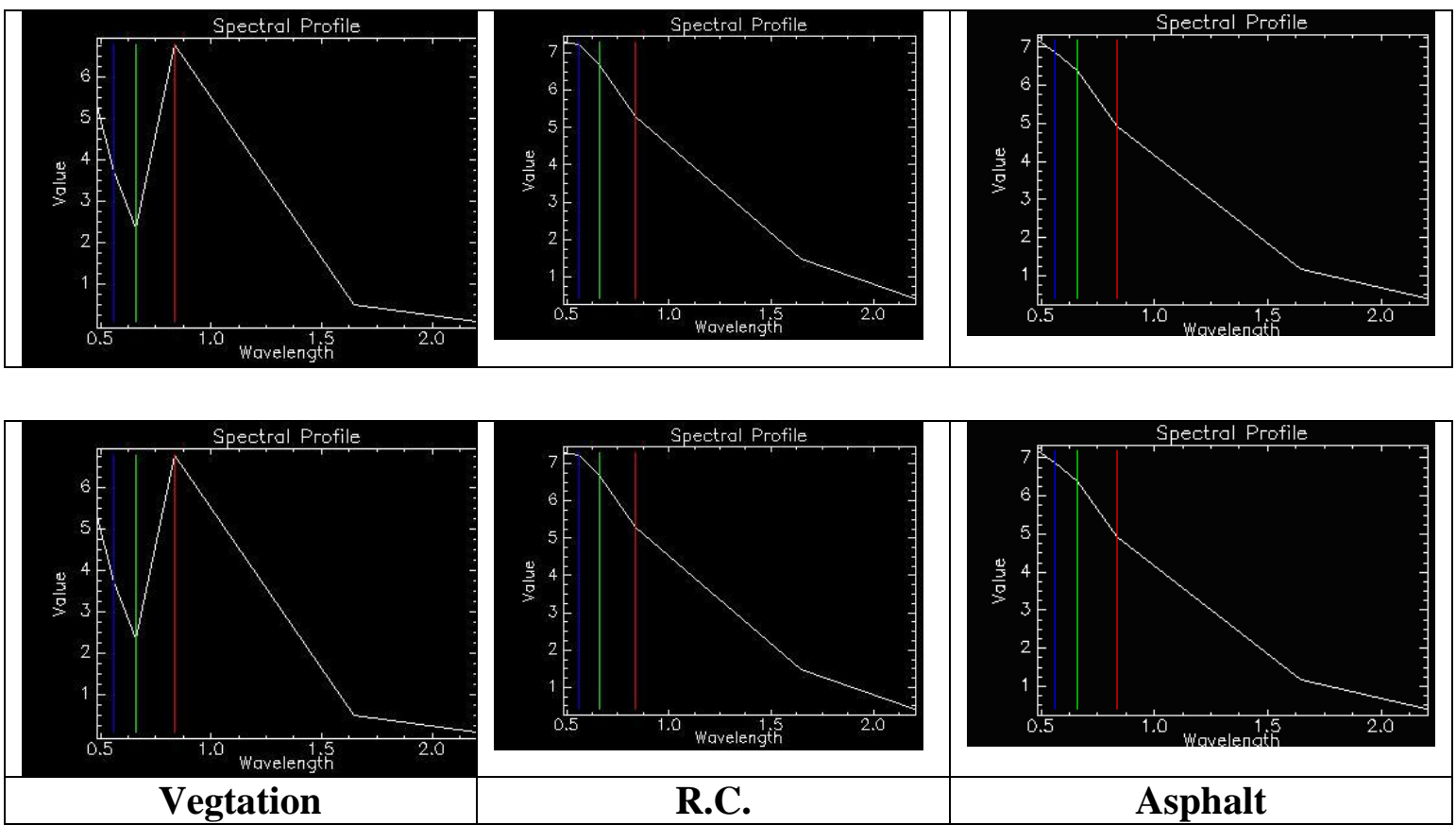

Vegtation

R.C.

Fig. (4) Spectral library from satellite image ETM+

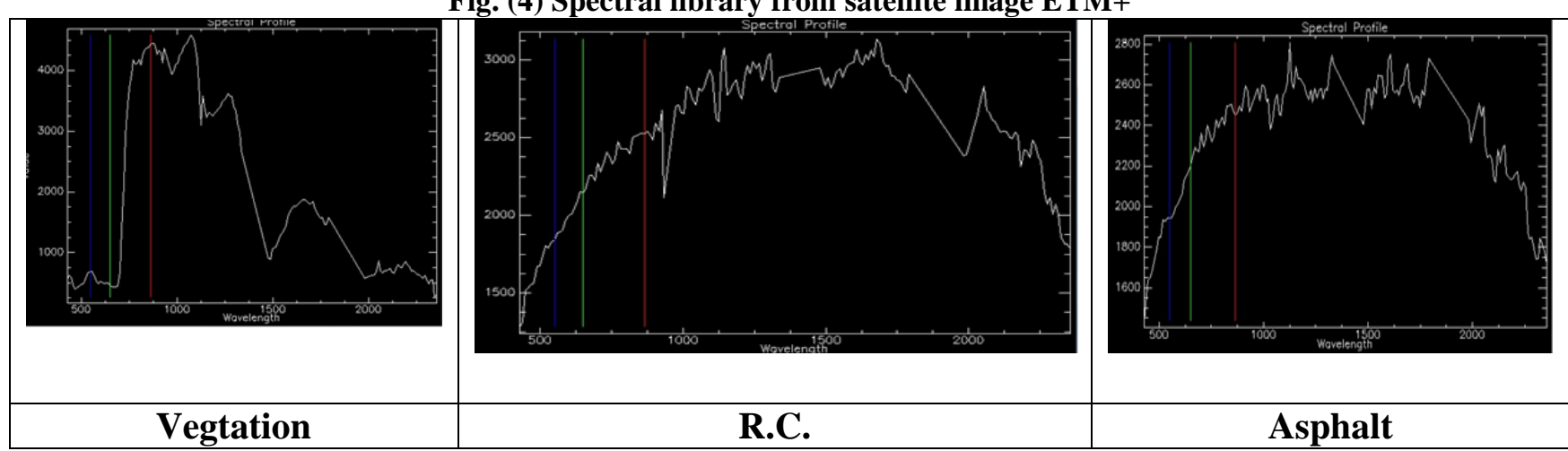

Fig. (5) Spectral library from Hyperion EO-1 


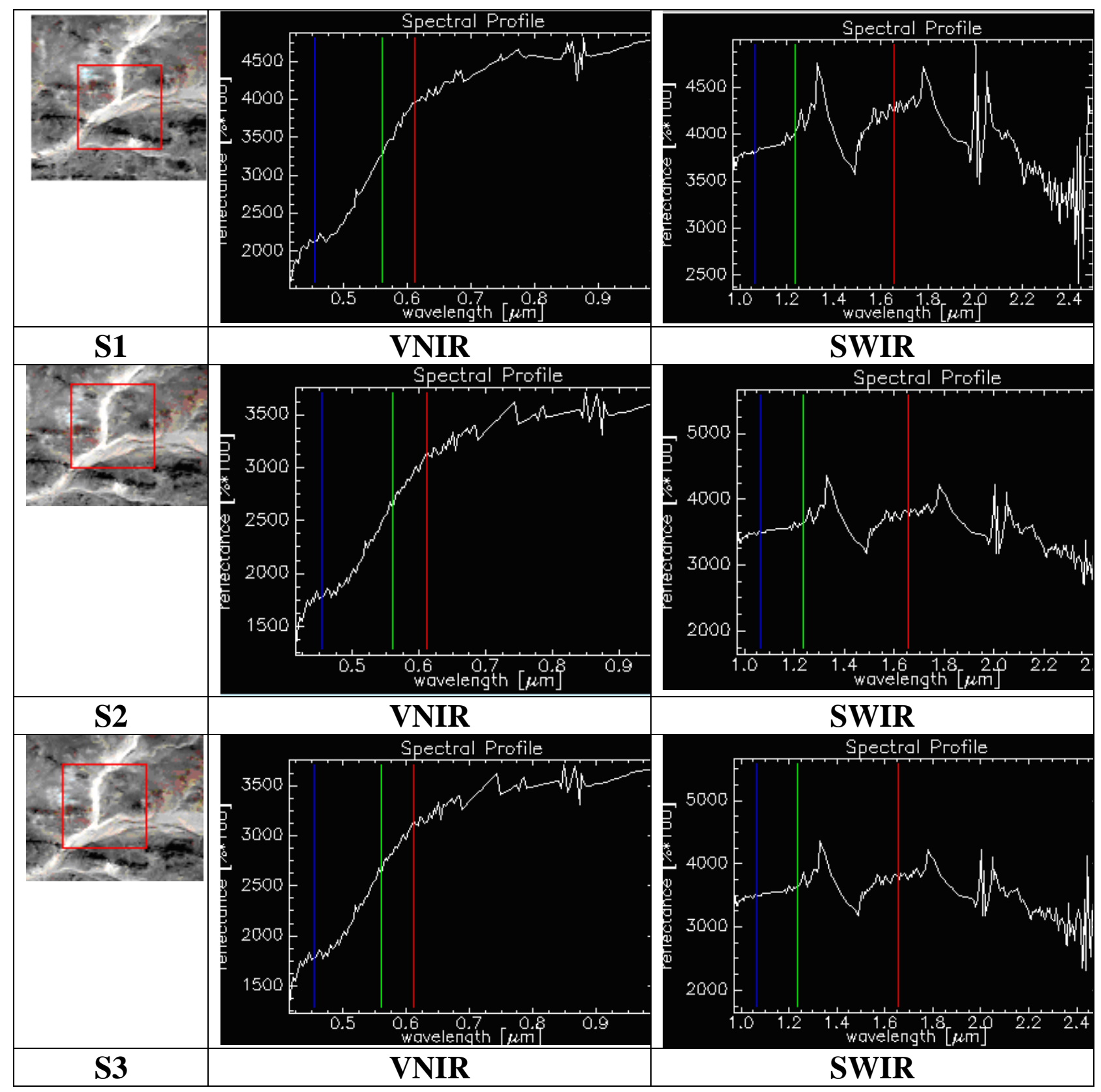

Fig. (6) Spectral library for three different topsoil materials have been extracted from airborne Hyspex

\section{CONCLUSIONS} camera VNIR and SWIR

Urban areas represent the hub of human activities characterized with high diversity of materials, different artificial, natural surface materials and mixtures of materials, within a highly mixed urban environment and complex geometries.

In this research, one can propose development of a spectral library for urban area using field, lab and airborne imaging spectrometry. Spectral library proposed to be used for calibrating and validating Hyperspectral data and for the purpose of accurate detection surface materials and improve large scale mapping. Field imaging spectrometers ASD are capable to construct accurate spectral library in case using contact prop. Spectra of samples of natural and artificial collected from field and measured using two laboratory hyperspectral camera VNIR and SWIR need additional studies and calibration. Satellite and airborne imaging spectrometers provide a large number of wavelengths at fine spatial resolution are capable to collect spectra and construct spectral library. From the obtained results spectra of roofs, roads, sidewalks and other urban features of varying materials and conditions, transportation surfaces (roads, sidewalks) and others has a big similarity and variable with environmental conditions and age of materials. 
Construction complete spectral libarary for any country is very essential for many remote sensing applications but it is hard task and very expensive and timely.

\section{REFERENCES}

1- Ben-Dor, E., Levin N., \& Saaroni, H., 2001 "A spectral-based Recognition of the Urban Environment Using the Visible and Near-infrared Spectral Region $(0.4-1.1 \mathrm{~m})$ : A Case Study over Tel- Aviv" International Journal of Remote Sensing, VoI. 22 no. (11), pp. 2193-2218

2- Buckingham, R., Staenz, K. \& Hollinger, A. 2002 "Review of Canadian Airborne and Space Activities in Hyperspectral" Canadian Aeronautics and Space Journal, pp. 115-121.

3- Chisense C., 2012 "Classification of Roof Materials Using Hyperspectral Data" International Archives of the Photogrammetry, Remote Sensing and Spatial Information Sciences, VoI. XXXIX-B7 ISPRS Congress, Melbourne, Australia

4- Cocks, T., Jenssen, R., Stewart, A., Wilson, I.; Shields, T., 1998 "The HYMAP Airborne Hyperspectral Sensor: The System, Calibration, and Performance" In Proceedings of the 1st EARSEL Workshop on Imaging Spectroscopy, Zurich, Switzerland, pp. 37-42.

5- Fleischer, Michael, 1980, "Glossary of Mineral Species" Mineralogical Record, Tucson, pp. 192.

6- Fleischer, Michael, and Mandarino, J.A., 1995, "Glossary of Mineral Species" The Mineralogical Record Inc., Tucson, pp. 265 \&pp. 280.

7- Gerylo, G.R., Hall, R.J., Franklin, S.E. and Smith, L., 2002 "Empirical Relations between Landsat TM Spectral Response and Forest Stands Near Fort Simpson, Northwest Territories, Canada" Canadian Journal of Remote Sensing, 28, pp. 68-79.

8- Herold M ., Roberts D. A. Gardner, M. E., Dennison P. E. , 2004 "Spectrometry for Urban Area Remote Sensing-Development and Analysis of a Spectral Library from 350 to $2400 \mathrm{~nm}$ " Remote Sensing of Environment VoI. 91 pp. 304-319

9- Hyspex, 2010 "Hyspex Airborne Systems Users Manual Version 2" Norsk electro optikk AS 2010

10- Klein, C., and Hurlbut, Jr., C.S., 1985 "Manual of Mineralogy" after James D.Dana, 21st Edition, New York, John Wiley, pp. 681.

11- Lamyaa Taha and Atti Shahin, 2013 "Assessment of Cartographic Potential of Airborne Hyperspectral Data for Large Scale Mapping" Recent Advances in Image, Audio and Signal Processing, ISBN: 978-960-474-350-6

12- Rosa M. C., Lorenzo F., Simone P., Stefano P. and Federico S., 2008 "Hyperspectral Sensor Data Capability for Retrieving Complex Urban Land Cover in Comparison with Multispectral Data: Venice City Case Study, Italy" Sensors, 8(5), 3299-3320; doi:10.3390/s8053299

13- Roberts, D.A., Gardner, M., Church, R., Ustin, S., Scheer, G. \& Green, R.O., 1998 "Mapping Chaparral in the Santa Monica Mountains Using Multiple Endmember Spectral Mixture Models" Remote Sensing of Environment. VoI. 65, pp. 267-279.

14- Roberts, D.A., S.L. Ustin, S. Ogunjemiyo, J. Greenberg, S.Z. Dobrowski, J. Chen, and T.M. Hinckley, 2004 "Spectral and Structural Measures of Northwest Forest Vegetation at Leaf to landscape Scales" Ecosystems VoI., 7 no. (5), pp. 545-562.

15- Roberts, D.A., Yamaguchi, Y., \& Lyon, R.J.P., 1985 "Calibration of Airborne Imaging Spectrometer Data to Percent Reflectance using Field Spectral Measurements" in Proceedings of the 19th International Symposium on Remote Sensing of Environment, Ann Arbor, Michigan, pp. 679-688.

16- Roberts, D.A., ADAMS, J.B., \& SMITH, M.O., 1993 "Discriminating Green Vegetation, Non- Photosynthetic Vegetation and Soils in AVIRIS Data" Rem. Sens. Environ., VoI. 44 (2/3), pp. 255-270.

17- Roberts, D. A. and M. Herold, 2004 "Infrared Spectroscopy in Geochemistry, Exploration and Remote Sensing" Mineral Association of Canada, Short Course Series Vol. 33, pp. 155181 .

18- USGS, $2013 \mathrm{http}: / /$ speclab.cr.usgs.gov/spectral.lib06/ds231/\#TOM

19- Vane, G.; Green, R.O.; Chrien, T.G.; Enmark, H.T.; Hansen, E.G.; Porter, W.M., 1993

"The airborne visible/infrared imaging spectrometer (AVIRIS)" Remote Sensing of

Environment, Vol. 44, pp. 27-143. 